\title{
Co-treatment of hydrogen sulfide and methanol in a single-stage biotrickling filter under acidic conditions
}

\author{
Yaomin Jin, María C. Veiga, Christian Kennes \\ Chemosphere Volume 68, Issue 6, June 2007, Pages 1186-1193 \\ DOI: 10.1016/j.chemosphere.2007.01.069
}

\begin{abstract}
Biofiltration of waste gases is cost-effective and environment-friendly compared to the conventional techniques for treating large flow rates of gas streams with low concentrations of pollutants. Pulp and paper industry off-gases usually contain reduced sulfur compounds, such as hydrogen sulfide and a wide range of volatile organic compounds (VOCs), e.g., methanol. It is desirable to eliminate both of these groups of compounds. Since the co-treatment of inorganic sulfur compounds and VOCs in biotrickling filters is a relatively unexplored area, the simultaneous biotreatment of $\mathrm{H}_{2} \mathrm{~S}$ and methanol as the model VOC was investigated. The results showed that, after adaptation, the elimination capacity of methanol could reach around $236 \mathrm{~g} \mathrm{~m}^{-3} \mathrm{~h}^{-1}$ with the simultaneous complete removal (100\%) of $12 \mathrm{ppm} \mathrm{H}_{2} \mathrm{~S}$ when the empty bed residence time is $24 \mathrm{~s}$. The $\mathrm{pH}$ of the system was around 2. Methanol removal was hardly affected by the presence of hydrogen sulfide, despite the low $\mathrm{pH}$. Conversely, the presence of the VOC in the waste gas reduced the efficiency of $\mathrm{H}_{2} \mathrm{~S}$ biodegradation. The maximal methanol removal decreased somewhat when increasing the gas flow rate. This is the first report on the degradation of methanol at such low $\mathrm{pH}$ in a biotrickling filter and on the co-treatment of $\mathrm{H}_{2} \mathrm{~S}$ and VOCs under such conditions.
\end{abstract}

\section{Keywords}

Acidophiles; pH; Fungi; Substrate competition; Oxygen limitation

\section{Introduction}

Biofiltration is an established waste gas treatment technology that may provide a costeffective solution for many industries facing emission problems (Kennes and Veiga, 2001). A biofilter consists of a packed bed of organic or synthetic material on which a microbial film is attached. When a contaminated air stream passes through the reactor, the pollutants are transferred to the biofilm, where they are biodegraded to simple end products, such as water and carbon dioxide in the case of non-halogenated volatile organic compounds (VOCs). Instead of using large amounts of thermal energy to destroy pollutants, or removing pollutants by transfer from one phase to another, biofilter systems harness the natural ability of microorganisms to degrade organic and inorganic contaminants biochemically into environmentally harmless end products at ambient temperature. Under adequate conditions, gas-phase bioreactors are more efficient than non-biological treatment processes for VOC removal (Kastner and Das, 2005). A biotrickling filter works in a similar manner to a biofilter, except that an aqueous phase is continuously trickled over the packing, and the filter bed is made of some synthetic or inert material, like plastic rings, open pore foam, or lava rock. The 
trickling solution contains essential inorganic nutrients such as nitrogen, phosphorous, and potassium, and is usually recycled.

To date, most lab-scale biofiltration studies address the removal of single pollutants under constant operating conditions. Such conditions are highly unusual at wastewater treatment plants and some other facilities. For instance, the malodorous emissions into the atmosphere from a pulp mill originate mainly from cooking, pulp washing, recovery boiler, evaporation, bark boiler, white liquor preparation, lime kiln, and pulp drying. These emissions tend to be a complex mixture of $\mathrm{H}_{2} \mathrm{~S}$ and other reduced sulfur compounds (such as dimethyl sulfide, dimethyl disulfide, and methyl mercaptan), as well as VOCs (such as methanol, terpenes, alcohols, phenol, ketones, and formaldehyde). The actual composition and individual concentrations often vary over time. In addition to being malodorous and toxic, some of these gases also undergo photochemical reactions in the atmosphere, contributing to the formation of photochemical oxidants, principally ozone.

Relatively little is known on the treatment of off-gases that contain both $\mathrm{H}_{2} \mathrm{~S}$ and VOCs. One problem encountered is that, as the sulfur in hydrogen sulfide is converted to sulfuric acid, the $\mathrm{pH}$ of the biofilm decreases. If the $\mathrm{pH}$ declines rapidly, biological activity in the biofilter may be inhibited, thereby reducing treatment effectiveness for organic compounds and sulfide, although $\mathrm{H}_{2} \mathrm{~S}$ is generally oxidized by Thiobacillus species that exhibit optimum activity at relatively acidic $\mathrm{pH}$. However, most Thiobacillus species are autotrophic organisms and, therefore, many of them do not use VOCs as a carbon source for growth. Most known heterotrophic bacteria capable of consuming VOCs prefer neutral $\mathrm{pH}$, and heterotrophic VOC-degraders are often more inhibited by acidification than $\mathrm{H}_{2} \mathrm{~S}$-degraders. In addition, acid conditions may hasten the deterioration of organic support media. These apparently conflicting $\mathrm{pH}$ optima for microbial activity are a challenge for developing bioreactors for the simultaneous removal of both $\mathrm{H}_{2} \mathrm{~S}$ and VOCs.

One solution is the treatment in a two-stage process as proposed by Chitwood et al. (1999). In the first stage, $\mathrm{H}_{2} \mathrm{~S}$ is oxidized in a biotrickling filter in which the $\mathrm{pH}$ drops as a result of $\mathrm{H}_{2} \mathrm{SO}_{4}$ accumulation. The $\mathrm{H}_{2} \mathrm{~S}$-free off-gas is then passed through a neutral$\mathrm{pH}$ biofilter for the removal of VOCs. Considerable savings could possibly be made if $\mathrm{H}_{2} \mathrm{~S}$ and VOC removal was combined in a single bioreactor. The same authors also investigated another solution for the treatment of mixed hydrogen sulfide and organic vapors in a rock packed pilot-scale biofilter (Chitwood and Devinny, 2001). The removal efficiencies of $\mathrm{H}_{2} \mathrm{~S}$ and $\mathrm{VOC}$ reached at $\mathrm{pH} 4$ were comparable to the values expected for a neutral-pH biofilter. However, lava rock is susceptible to dissolution at low-pH conditions (around 4). Recently, Cox and Deshusses (2002) reported that $\mathrm{H}_{2} \mathrm{~S}$ and toluene can be effectively treated simultaneously in a single-stage biotrickling filter. The $\mathrm{pH}$ of operation (4.5 or 7.0) did not greatly affect the performance of $\mathrm{H}_{2} \mathrm{~S}$ and

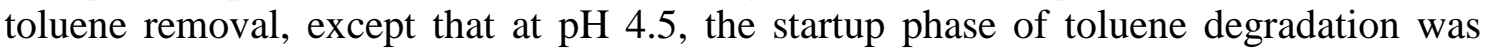
relatively long. Recent research at publicly owned treatment works has shown that $\mathrm{H}_{2} \mathrm{~S}$ and low concentrations of VOCs can be co-treated in biofilters without $\mathrm{pH}$ control.

In our previous research, the autotrophic biodegradation of hydrogen sulfide as single pollutant was studied in a low-pH biotrickling filter (Jin et al., 2005a and Jin et al., 2005b). However, hydrogen sulfide and VOCs such as methanol, formaldehyde, methyl ethyl ketone, are often found together in waste air streams. Since the co-treatment of 
$\mathrm{H}_{2} \mathrm{~S}$ and VOCs in biotrickling filters is a relatively unexplored area, and autotrophic microorganisms do not use methanol as a carbon source for growth, the objective of this research was to investigate the feasibility of using a single-stage low-pH biotrickling filter to treat a mixture of methanol and $\mathrm{H}_{2} \mathrm{~S}$. Methanol was added to an originally autotrophic low-pH $\mathrm{H}_{2} \mathrm{~S}$-degrading reactor to determine to what extent the organic compound could be removed.

\section{Material and methods}

\subsection{Experimental setup}

The schematic of the biotrickling filter used in this study is shown in Fig. 1 and has been described previously in detail (Jin et al., 2005a). It is a cylindrical packed bed reactor made of glass, $75 \mathrm{~mm}$ in diameter and $700 \mathrm{~mm}$ in height, filled with polypropylene Pall rings of a nominal height of $15 \mathrm{~mm}$. The total height of the packed bed was $640 \mathrm{~mm}$. The Pall ring bed had an initial porosity of $91 \%$ and a specific surface area of $350 \mathrm{~m}^{2} \mathrm{~m}^{-3}$. This inert synthetic packing material was used to exclude any carbon source other than methanol and prevent complications arising from bed compaction and aging over the experimental period. The glass column contained four equidistant sampling ports. All fittings, connections and tubings were made of Teflon. $\mathrm{H}_{2} \mathrm{~S}$ was introduced by passing the gas stream over a $\mathrm{H}_{2} \mathrm{SO}_{4}$ solution into which a solution of $\mathrm{Na}_{2} \mathrm{~S}$ was dripped. Gas phase $\mathrm{H}_{2} \mathrm{~S}$ concentrations were regulated by changing the $\mathrm{Na}_{2} \mathrm{~S}$ concentration and/or dripping rate. Methanol was introduced into the gas by saturating a side air stream sparged into a bottle filled with pure methanol. The resulting waste gas was introduced through the bottom of the column for countercurrent flow operation (Fig. 1). The gas flow rate was maintained constant at $7 \mathrm{l} \mathrm{min}^{-1}$, corresponding to an empty bed residence time (EBRT) of $24 \mathrm{~s}$. The aqueous mineral medium was continuously recirculated over the packed bed using a peristaltic pump (model 323E/D, Watson-Marlow Limited, Falmouth Cornwall, England) at a constant volumetric flow rate of $2.77 \mathrm{l} \mathrm{h}^{-1}$. The nutrient solution of the biotrickling filter was renewed every day. The biotrickling filter's performance was estimated by calculating the elimination capacity and removal efficiency at different loads, according to equations defined in the literature (Kennes and Veiga, 2001). All the experiments were conducted at room temperature $\left(20-25^{\circ} \mathrm{C}\right)$.

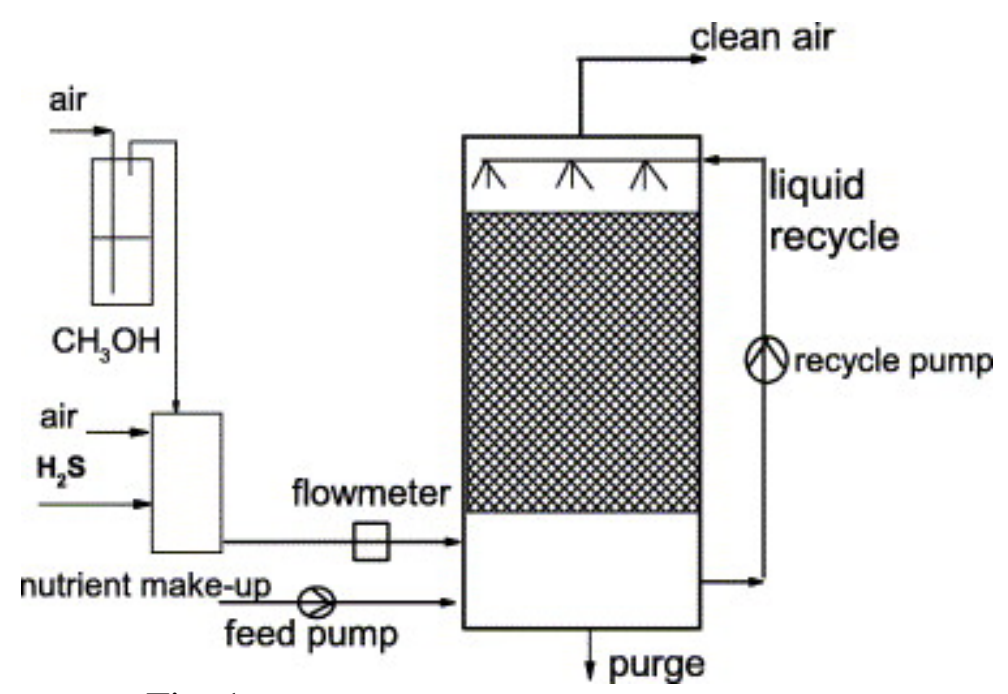

Fig. 1. Schematic of the laboratory scale biotrickling filter. 


\subsection{Analytical methods}

The concentration of methanol in the gas phase was measured with a gas chromatograph Hewlett-Packard 5890 series II equipped with a flame ionization detector (FID). The characteristics of the TRACER TR-WAX column were: $0.32 \mathrm{~mm}$ internal diameter, $50 \mathrm{~m}$ long with $1.2 \mu \mathrm{m}$ thickness. The gas flow rates were as follows: $\mathrm{H}_{2}, 30 \mathrm{ml} \mathrm{min}^{-1}$, and air, $300 \mathrm{ml} \mathrm{min}^{-1}$. The inlet and outlet gas streams, as well as air between the biofilter sections, were sampled. Helium was used as the carrier gas at a flow rate of $2.0 \mathrm{ml} \mathrm{min}{ }^{-1}$. The methanol concentration was determined at the oven temperature of $120{ }^{\circ} \mathrm{C}$ and using a FID at $250^{\circ} \mathrm{C}$. Inlet and outlet $\mathrm{H}_{2} \mathrm{~S}$ concentrations were determined using a gas sensor (Dräger Sensor XSEC $\mathrm{H}_{2} \mathrm{~S}$ HC6809180). The $\mathrm{pH}$ of the nutrient solution was measured with a Crison $\mathrm{pH}$-meter 507, using a combined glass electrode. Samples of packing from the biotrickling filter were prepared for observations under the electron microscope according to a standard procedure as previously reported (Jin et al., 2005b). Examination was performed with a JEOL JSM-6400 SEM working at a voltage of $20 \mathrm{kV}$ and a working distance of $15 \mathrm{~mm}$, and with Oxford Instruments EDX equipment. Samples were photographed extensively to ensure that representative images of the filter bed had been taken. From the difference between the inlet and outlet values of a manometer connected to the inlet and outlet ports of the reactor, pressure drop was calculated and normalized per meter packing height.

\section{Results and discussion}

\subsection{Initial performance of an originally autotrophic $\mathrm{H}_{2} \mathrm{~S}$-treating biotrickling filter after methanol addition}

Methanol was supplied in the range of 18 to $81 \mathrm{ppm}$ to allow for the determination of a possible positive or negative effect of an organic carbon source as $\mathrm{CH}_{3} \mathrm{OH}$ on $\mathrm{H}_{2} \mathrm{~S}$ removal in an originally autotrophic system.

Fig. 2 shows that when $\mathrm{CH}_{3} \mathrm{OH}$ was added at concentrations ranging from 18 to $81 \mathrm{ppm}$, a gradual decrease in the removal efficiency of $\mathrm{H}_{2} \mathrm{~S}$ was observed as the gas concentration of $\mathrm{CH}_{3} \mathrm{OH}$ increased. The maximum elimination capacity of $\mathrm{H}_{2} \mathrm{~S}$ dropped from $23.8 \mathrm{~g} \mathrm{~m}^{-3} \mathrm{~h}^{-1}$ at the lowest methanol concentrations to $6.4 \mathrm{~g} \mathrm{~m}^{-3} \mathrm{~h}^{-1}$ at the highest VOC concentration. Autotrophic microorganisms were originally dominant in the biotrickling filter, using $\mathrm{CO}_{2}$ as carbon source instead of $\mathrm{CH}_{3} \mathrm{OH}$ for $\mathrm{H}_{2} \mathrm{~S}$ removal, but the presence of $\mathrm{CH}_{3} \mathrm{OH}$ caused a gradual growth of heterotrophic organisms and a decrease of the autotrophic activity as evidenced by the decrease of $\mathrm{H}_{2} \mathrm{~S}$ removal. 


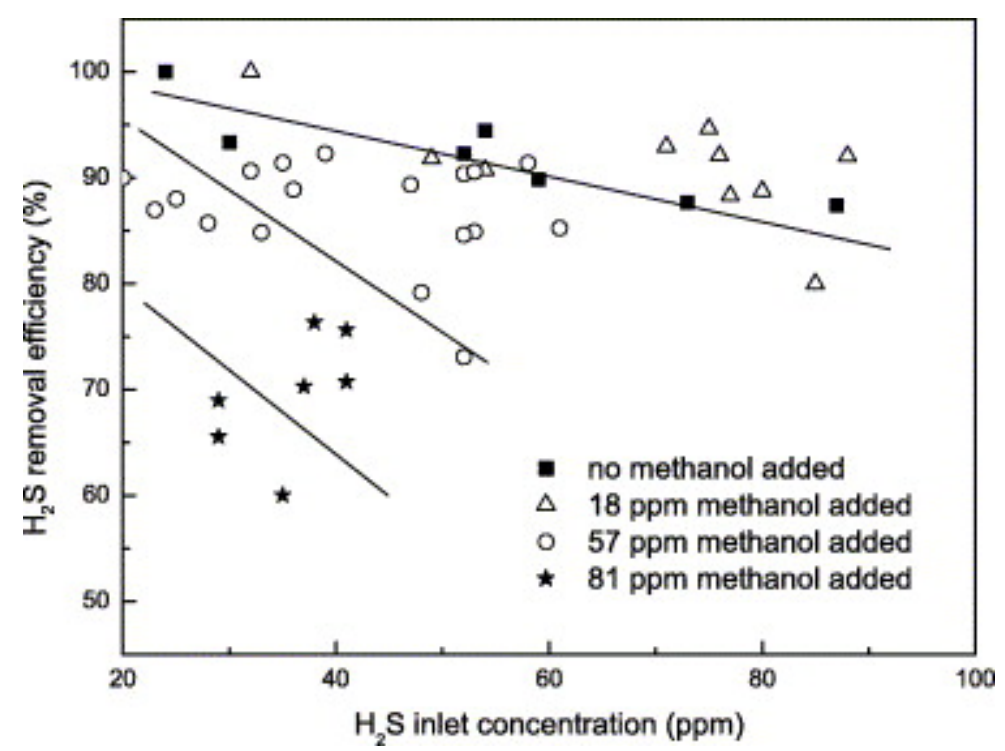

Fig. 2.

Influence of methanol on the performance of a biotrickling filter removing $\mathrm{H}_{2} \mathrm{~S}$.

Conversely, the elimination capacity of $\mathrm{CH}_{3} \mathrm{OH}$ did gradually increase from 2.7 to $11 \mathrm{~g} \mathrm{~m}^{-3} \mathrm{~h}^{-1}$ during that same period (Fig. 3). This value is much smaller than the maximum elimination capacities reported in the literature, which range from 50 to $250 \mathrm{~g} \mathrm{~m}^{-3} \mathrm{~h}^{-1}$ (Sologar et al., 2003). This could result from the very low $\mathrm{pH}$ of the filter bed, around 2, which is generally considered not optimum for bacterial methanol degradation. The optimum $\mathrm{pH}$ for VOC-degrading microorganisms is usually around 7. Nevertheless, adaptation to acidic conditions is possible as will be shown below in subsequent experiments. On the other hand, only $\mathrm{H}_{2} \mathrm{~S}$ was initially fed to the reactor (Jin et al., 2005a and Jin et al., 2005b) and therefore hardly any methanol biodegrading microorganisms were originally present in the filter bed, which is another reason that explains the limited methanol removal. The addition of $\mathrm{CH}_{3} \mathrm{OH}$ allowed the gradual growth of heterotrophs utilizing that VOC as carbon source. The removal efficiency of $\mathrm{CH}_{3} \mathrm{OH}$ did first increase from $58 \%$ to $65 \%$ and then decreased to $52 \%$ at inlet concentrations of 18,57 , and $81 \mathrm{ppm}$, respectively while maintaining the inlet $\mathrm{H}_{2} \mathrm{~S}-$ concentration at 12 ppm (Fig. 3). 


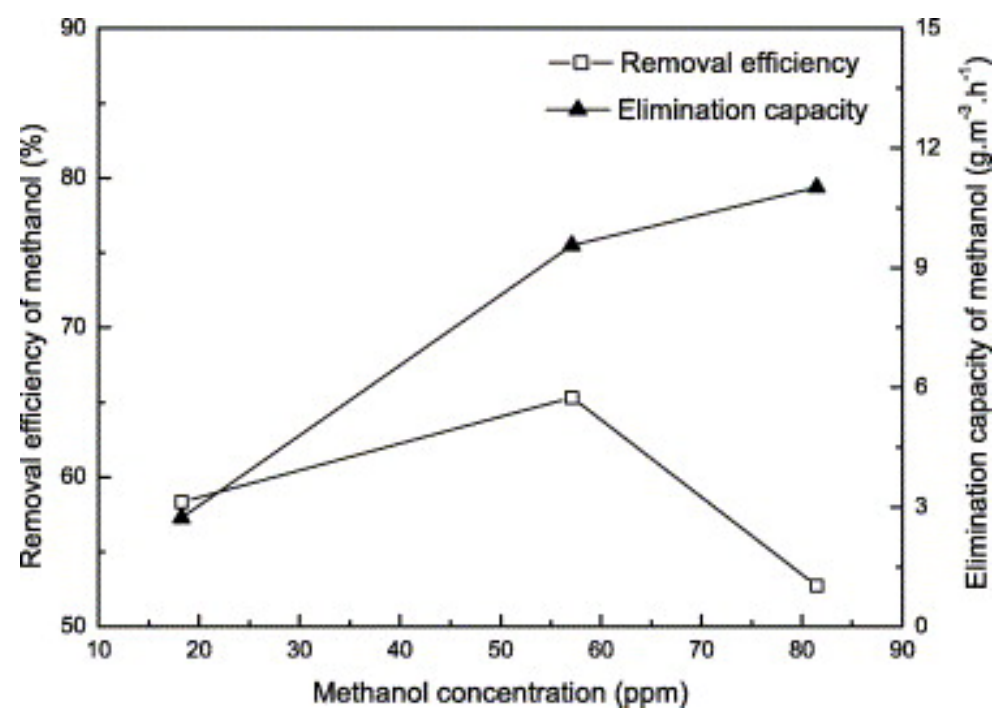

Fig. 3.

Removal efficiency and elimination capacity of $\mathrm{CH}_{3} \mathrm{OH}$.

\subsection{Improvement of methanol removal after new inoculation}

In order to try to improve the removal of methanol, fresh activated sludge was inoculated into the reactor. After that, the removal of methanol improved and the methanol inlet concentration was then increased. The $\mathrm{pH}$ of operation was relatively constant, around 2, as a result of $\mathrm{H}_{2} \mathrm{~S}$ degradation. During the first $20 \mathrm{~d}$, although the inlet concentration was increased daily, the removal efficiency always remained $100 \%$ (Fig. 4). This means that the methanol degrading microorganisms started to grow after the new inoculation. At the same time, the removal of $\mathrm{H}_{2} \mathrm{~S}$ reached $100 \%$ at an inlet concentration of $12 \mathrm{ppm}$. After this new start-up period, the removal efficiency of methanol remained around 95\% with the inlet concentrations between 450 and 700 ppm in the following steady states.

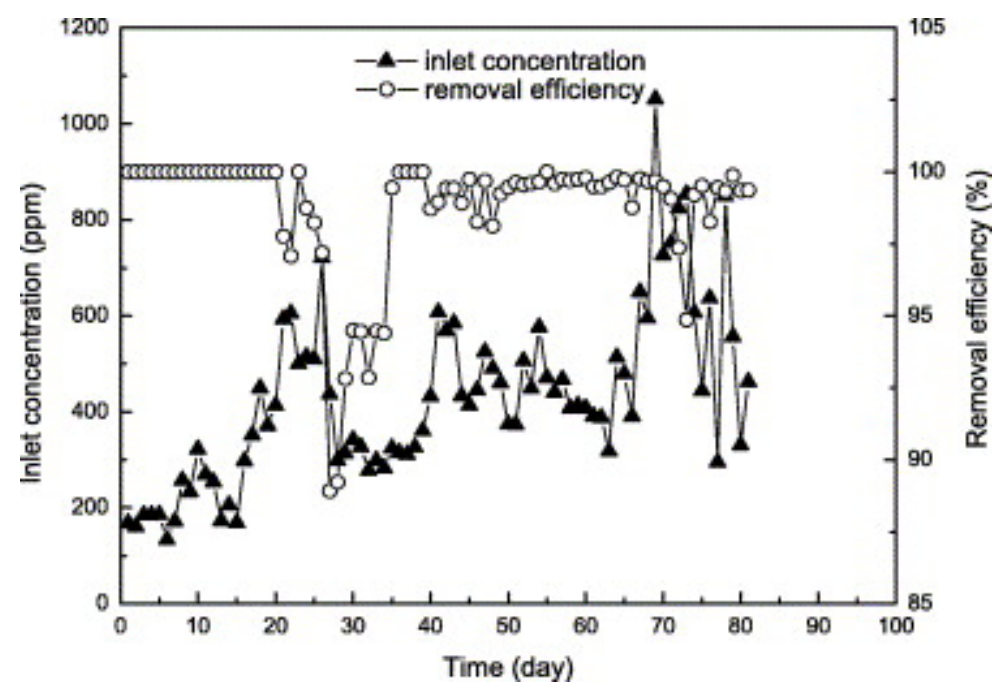

Fig. 4.

Methanol removal with time after inoculation of fresh activated sludge. 
To establish operating criteria necessary to scale-up the biotrickling filter, the relationship between the inlet loading of methanol and the elimination capacity was estimated. The results are reported in Fig. 5. The elimination capacity is defined as the amount of pollutant degraded per unit time, normalized to the volume of packed bed. As shown in Fig. 5, the relationship between the load and the removal rate rises linearly and the critical load (i.e., deviation from the complete removal capacity) was not reached yet when the elimination capacity was $160 \mathrm{~g} \mathrm{~m}^{-3} \mathrm{~h}^{-1}$. Besides, the removal efficiency of methanol was always above $97.5 \%$ during most of the experimental period at inlet concentrations below 1100 ppm (Fig. 5).

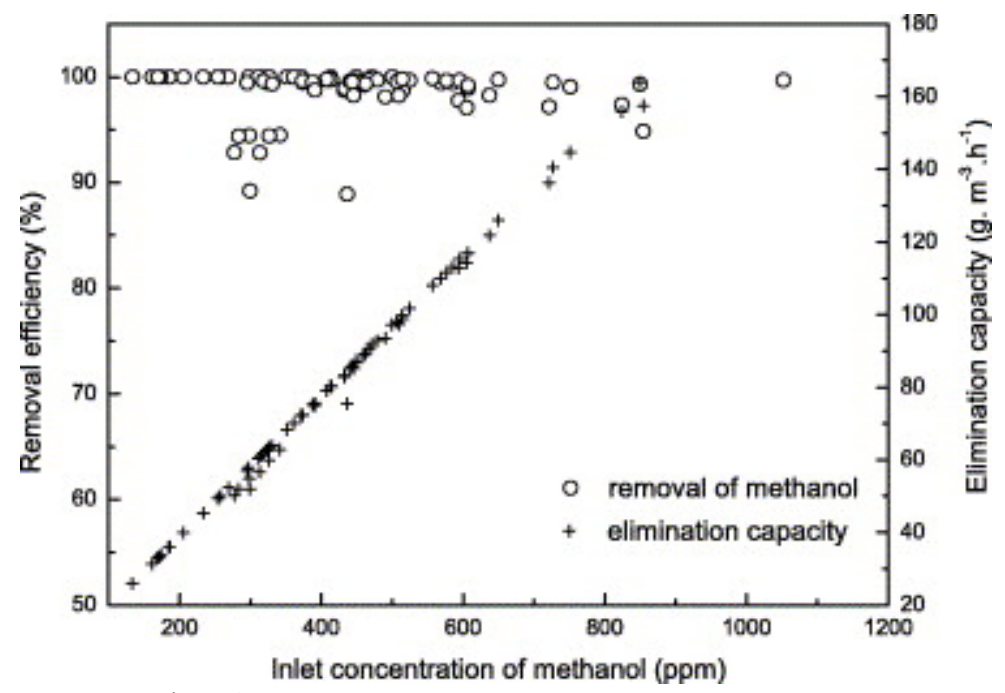

Fig. 5.

Elimination capacity of methanol versus its inlet concentration in the cotreatment of $\mathrm{H}_{2} \mathrm{~S}$ and methanol in a biotrickling filter. Removal efficiency as a function of the inlet concentration data include three months of continuous operation. The removal of $\mathrm{H}_{2} \mathrm{~S}$ reached $100 \%$ with an inlet concentration of $12 \mathrm{ppm}$.

Until now, there is no report on the co-treatment of methanol and $\mathrm{H}_{2} \mathrm{~S}$ at such low $\mathrm{pH}$. Thus, further research about this topic is quite necessary. This does also show that adaptation of heterotrophic VOC-degrading microorganisms to very low $\mathrm{pHs}$ is sometimes possible. The same was observed previously in an alkylbenzene-treating biofilter, in which bacteria as Pseudomonas sp. and Bacillus sp. were able to degrade the pollutants at a pH as low as 3.5 ( Veiga et al., 1999).

\subsection{Effect of the gas flow rate}

In Fig. 6 the measured trickling filter's elimination capacity is plotted for different inlet methanol concentrations at a constant liquid flow rate of $2.77 \mathrm{l} \mathrm{h}^{-1}\left(0.627 \mathrm{~m} \mathrm{~h}^{-1}\right)$ and at gas flow rates of 6,7 , and $10 \mathrm{l} \mathrm{min}^{-1}$, corresponding to superficial gas velocities of 81 , 95, and $136 \mathrm{~m} \mathrm{~h}^{-1}$ and EBRT of 28, 24, and $17 \mathrm{~s}$. From this figure, it can be observed that the removal efficiency decreased when increasing the gas flow rate over all the concentration range studied. 


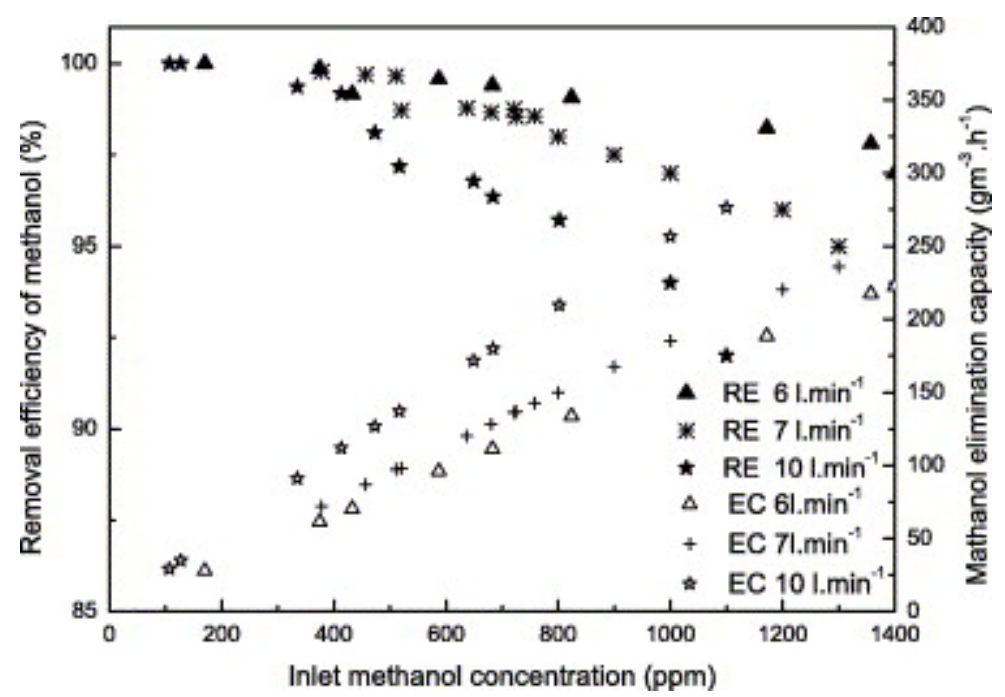

Fig. 6.

Removal efficiency of methanol in the biotrickling filter as a function of the inlet concentration, at different flow rates of the gas streams.

At $10 \mathrm{l} \mathrm{min}^{-1}$ a maximum methanol elimination capacity of $276 \mathrm{~g} \mathrm{~m}^{-3} \mathrm{~h}^{-1}$ was obtained, while at 6 and $7 \mathrm{lmin}^{-1}$ the maximum elimination capacities were 222 and $236 \mathrm{~g} \mathrm{~m}^{-3} \mathrm{~h}^{-1}$, respectively. At the same time, the elimination capacity of $\mathrm{H}_{2} \mathrm{~S}$ was $2.5 \mathrm{~g} \mathrm{~m}^{-3} \mathrm{~h}^{-1}$. It seems that the elimination capacity of methanol increased with the gas flow rate. This may be due to the high turbulence at high gas flow rates making the liquid film become thinner and enhancing the mass transfer of methanol.

\subsection{Substrate competition and stratification of biodegradation}

In order to gain insight in the biodegradation mechanisms of the $\mathrm{H}_{2} \mathrm{~S}$ and methanol mixture, their concentrations were measured at different heights in the column. Fig. 7 shows concentration profiles of methanol and $\mathrm{H}_{2} \mathrm{~S}$ along the length of the biotrickling filter. For $25 \mathrm{ppm} \mathrm{H}_{2} \mathrm{~S}$ and $500 \mathrm{ppm}$ methanol, the results show that methanol was completely eliminated in the first two-thirds of the column with most of the removal (75\%) taking place over the first one-third, while $\mathrm{H}_{2} \mathrm{~S}$ was degraded at a quite constant rate over the complete height of the column. These results show a stratification in terms of biodegradation. Methanol was metabolized before $\mathrm{H}_{2} \mathrm{~S}$. Two hypotheses can be suggested regarding the microbial populations: (1) there was competition between populations and the different populations colonizing the Pall ring-packed biotrickling filter were either specialized in the elimination of methanol or in $\mathrm{H}_{2} \mathrm{~S}$ removal; (2) there was competition between substrates and, in such case, the bacterial community remained roughly the same over the height of the column, but the more easily biodegradable methanol was used first for microbial metabolism when it was present in the gaseous effluent. 


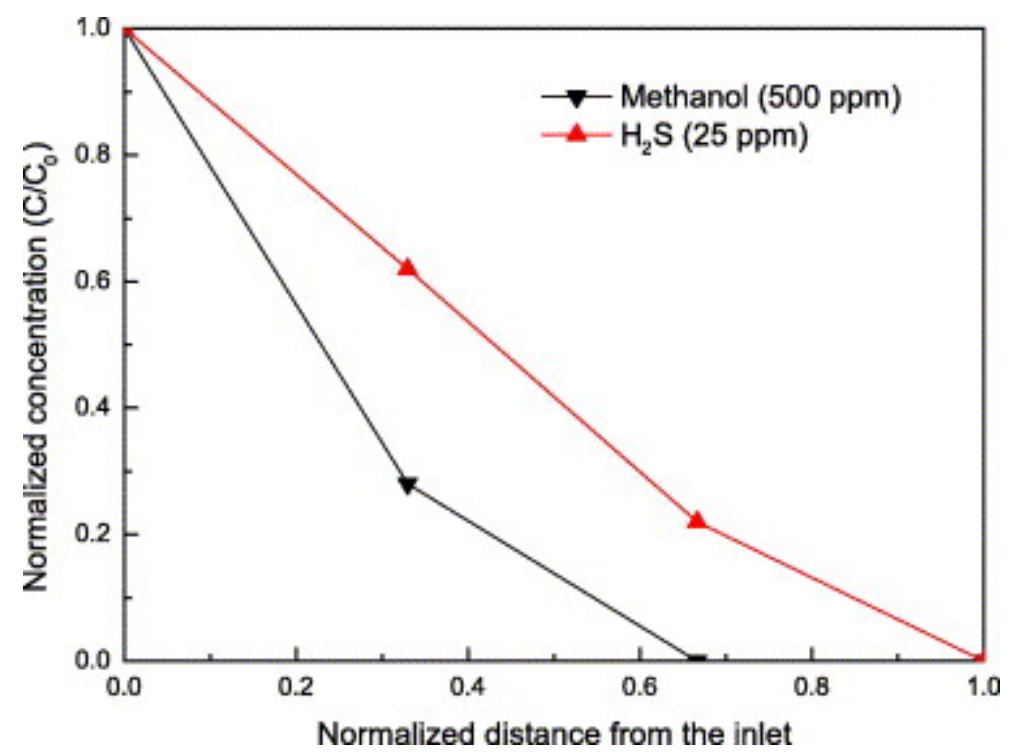

Fig. 7.

Methanol and $\mathrm{H}_{2} \mathrm{~S}$ concentration profiles along the length of the biotrickling filter.

Other researchers observed a similar behavior when feeding mixed pollutants, although in all of those studies, only VOC mixtures were fed and no inorganic pollutants as $\mathrm{H}_{2} \mathrm{~S}$. Ergas and coworkers observed that toluene elimination occurred in the first centimeters of the column and dichloromethane (DCM) elimination occurred in the second half of the column when treating a mixture of toluene and DCM in a biofilter (Ergas et al., 1996). The authors proposed a stratification in terms of biodegradation and suggested that two different microbial communities colonized the reactor at steady state. Deshusses et al. (1999) observed a stratification in terms of degradation when treating a mixture of ethyl acetate and toluene. Ethyl acetate was degraded in the inlet part of the column and toluene elimination occurred in the second half of the column. Furthermore, the authors highlighted that microorganisms that colonized the first centimeters of the column had the potential to degrade toluene. They suggested that substrate competition occurred and that the microorganisms degraded preferentially the more easily biodegradable compound. Aizpuru and coworkers also reported that a stratification of biodegradation occurred in a biofilter treating a mixture of methanol, acetone, methyl ethyl ketone, methyl isobutyl ketone, butyl and ethyl acetates, toluene, ethylbenzene, xylene, dichloromethane, and 1,2-dichloroethane (Aizpuru et al., 2001). The oxygenated compounds were metabolized before the aromatic and halogenated ones. Hwang et al. (2003) reported the degradation of ethyl acetate and toluene mixtures in a biofilter using different combinations of bacterial cultures and changes in the degradabilities of ethyl acetate and toluene induced by substrate combination and microbial community competition were observed. In our present study, however, if the second hypothesis mentioned above is correct, the $\mathrm{H}_{2} \mathrm{~S}$-degrading population should be facultative heterotrophic methanol degrader as well. The existence of the heterotrophic $\mathrm{H}_{2} \mathrm{~S}$ degraders has been reported in the literature (Lens and Pol, 2000). Nevertheless, it is expected that both heterotrophic methanol degraders and autotrophic $\mathrm{H}_{2} \mathrm{~S}$ degraders are present as two different populations in the reactor. Since the bioreactor was originally fed $\mathrm{H}_{2} \mathrm{~S}$ as single pollutant, the autotrophic population is most probably present in the full filter bed volume explaining the linear removal rate observed in Fig. 7, while the heterotrophic population, developing after the inoculation of fresh sludge, colonized the 
inlet zone of the packing explaining the faster methanol removal in that zone (Fig. 7). Preliminary data on the microbiological characterization of the biofilm suggest that the main acid-tolerant methanol degrader in the inlet zone of the filter bed is a yeast according to microscopic observations and batch experiments.

\subsection{Oxygen limitation}

Oxygen limitation led to the partial transformation of $\mathrm{H}_{2} \mathrm{~S}$ to elemental sulfur with the simultaneous removal of methanol. Fig. 8 shows spent Pall rings after introduction of methanol into the originally autotrophic biotrickling filter. The rod-shaped material in the spent Pall rings was mainly condensed elemental sulfur, as was also confirmed by the subsequent elemental analysis. Compared to the results obtained during the autotrophic $\mathrm{H}_{2} \mathrm{~S}$ biodegradation, the sulfur content in the present experiment was higher than in that previous study, reaching values of $70 \%$ and $62 \%$, respectively. Sulfur production from the partial oxidation of sulfide instead of the complete oxidation to sulfate may be due to oxygen limitation caused by preferred methanol consumption because of its good biodegradability. According to the stoichiometry of the aerobic biological sulfide oxidation, oxygen is the key parameter that controls the level of oxidation, according to the following equations:

$$
\begin{aligned}
& 2 \mathrm{HS}^{-}+\mathrm{O}_{2} \rightarrow 2 \mathrm{~S}^{\circ}+2 \mathrm{OH}^{-} \quad \Delta G^{0}=-129.50 \mathrm{~kJ} \mathrm{~mol}^{-1} 2 \\
& 2 \mathrm{HS}^{-}+4 \mathrm{O}_{2} \rightarrow 2 \mathrm{SO}_{4}^{2-}+2 \mathrm{H}^{+} \quad \Delta G^{0}=-732.58 \mathrm{~kJ} \mathrm{~mol}^{-1}
\end{aligned}
$$
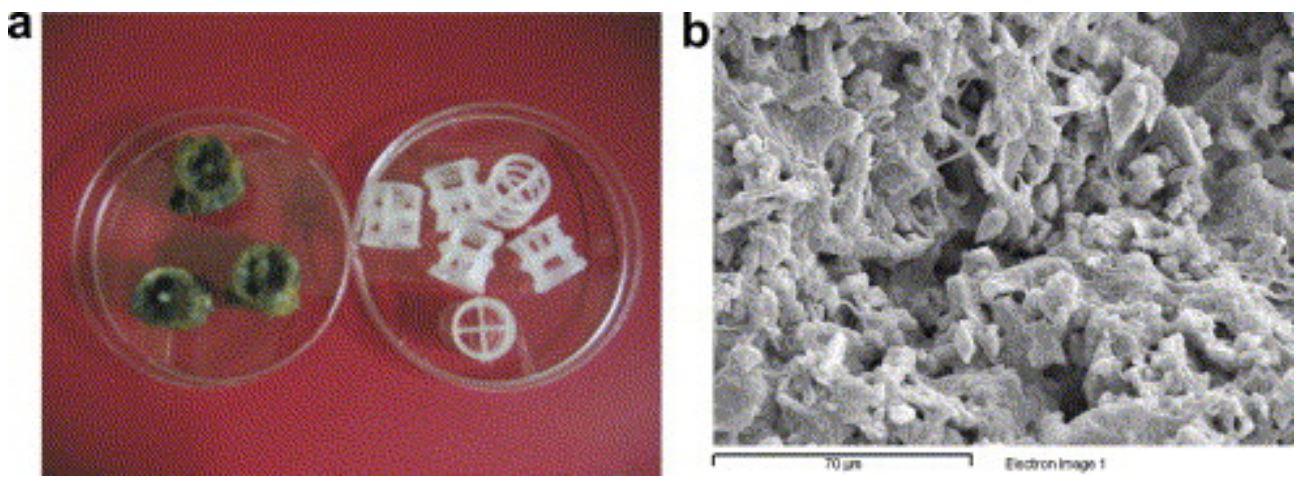

Fig. 8.

Pictures of Pall rings. (a) Clean Pall rings (right) and rings covered with biomass (left). (b) SEM photo of Pall rings from a bioreactor treating methanol and $\mathrm{H}_{2} \mathrm{~S}$.

Sulfur production (Eq. (1)) results from the partial oxidation of sulfide instead of a complete oxidation to sulfate (Eq. (2)) when oxygen is limited. Additionally, lower energy consumption is required because the oxidation to sulfur requires four-fold less oxygen.

Other researchers also observed similar results. Buisman et al. (1990) reported that, at sulfide concentrations below $20 \mathrm{mg} \mathrm{l}^{-1}$, the oxygen concentration should be kept low (below $1 \mathrm{mg} \mathrm{l}^{-1}$ ) to limit sulfur oxidation to sulfate. Janssen et al. (1995) found that the optimal oxygen to sulfide molar ratio to improve the sulfur production was about 0.7. The same authors described the performance of a sulfide-oxidizing expanded-bed 
reactor that was designed for elemental sulfur formation (Janssen et al., 1997). In that reactor, the aeration of the liquid phase and the oxidation of sulfide were spatially separated. Sulfur sludge with good settling properties, which consisted mainly of elemental sulfur (92\%) and biomass (2\%), was obtained.

The partial oxidation of sulfide presents environmental implications as elemental sulfur can be removed by sedimentation. However, long term bioreactor operation may result in the gradual accumulation of sulfur inside the filter bed, blockage of pores and apparently channeling. This will lead to a continuous decrease of $\mathrm{H}_{2} \mathrm{~S}$ removal, as observed in a previous study on $\mathrm{H}_{2} \mathrm{~S}$ removal without methanol (Jin et al., 2005b). Moreover, when a VOC as methanol is present in the waste gas, the growth of heterotrophs is much faster than autotrophs and also contributes significantly to the clogging of the bioreactor. The filter bed with accumulated biomass and sulfur products suffers channeling problems and subsequently decreases in the performance, that may be confused with substrate competition. However, there appears to be little impact of multiple substrates on system performance once acclimation has occurred.

\subsection{Pressure drop}

The filter bed's pressure drop is a key aspect of biofilter performance. It affects the energy consumption of the blower, which contributes most to the operation costs. The variations of pressure drop in the filter column are shown in Fig. 9. During previous experiments on the autotrophic biodegradation of $\mathrm{H}_{2} \mathrm{~S}$ as single pollutant, the variation of the pressure drop in the biotrickling filter was negligible (Jin et al., 2005a and Jin et al., 2005b). After introduction of methanol into the bioreactor, the pressure drop did first slightly increase to around $10 \mathrm{~mm} \mathrm{H}_{2} \mathrm{O} \mathrm{m}^{-1}$ in $230 \mathrm{~d}$, while the removal of methanol increased simultaneously until the pressure drop of the bioreactor reached a critical value of $20 \mathrm{~mm} \mathrm{H}_{2} \mathrm{O} \mathrm{m}^{-1}$. The pressure drop increase probably resulted from the accumulation of sulfur product and biomass due to the continuous high inlet load of methanol. Under a methanol inlet loading rate of $150 \mathrm{~g} \mathrm{~m}^{-3} \mathrm{~h}^{-1}$, the removal efficiency of methanol first remained around 95\% (Fig. 9). With the increase of pressure drop, the removal efficiency dropped steeply and finally reached $15 \%$ as the pressure drop increased to $57 \mathrm{~mm} \mathrm{H}_{2} \mathrm{O} \mathrm{m}^{-1}$. Then, a relatively high liquid flow rate of $13.9 \mathrm{l} \mathrm{h}^{-1}$ was used for removing the excess biomass and generated sulfur. In this way, the pressure drop could be maintained again below $15 \mathrm{~mm} \mathrm{H}_{2} \mathrm{O} \mathrm{m}^{-1}$ and the performance was not affected. 


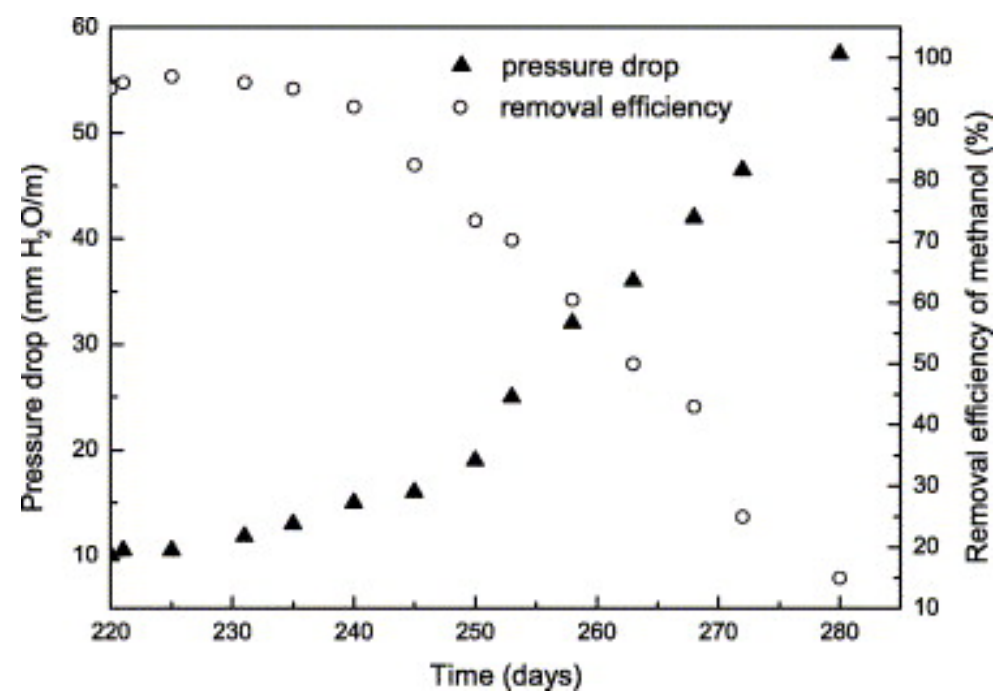

Fig. 9.

Variation of the pressure drop and performance of the biotrickling filter under a methanol inlet loading rate of $150 \mathrm{~g} \mathrm{~m}^{-3} \mathrm{~h}^{-1}$.

Most of the time pressure drop increase is related to biofilm growth and clogging by biomass. For example, Liu et al. (1994) working with granular activated carbon columns for toluene removal, measured increased pressure drops of up to $1223 \mathrm{~mm}$ $\mathrm{H}_{2} \mathrm{O} \mathrm{m}^{-1}$ due to biomass accumulation resulting in airflow channeling. In general, the increase in pressure drop as a result of biomass development in biofilters can be explained by a decrease in the bed interparticle void space or the effective porosity or both and by the microbial degradation of the support matrix in the case of natural media, which result in decreased specific permeability. Although the effect of biomass accumulation on pressure drop has been reported, and has been studied in biotrickling filters treating gaseous streams (Sorial et al., 1997 and Okkerse et al., 1999), there has been little detailed, quantitative research on how to avoid this problem. Therefore, controlled formation of biomass in a trickle-bed reactor is a prerequisite to estimate its capacity and the continuity for waste gas treatment. Two ways are feasible to maintain the back pressure low and a high bioreactor performance: (1) reduce the biomass formation rate, or (2) remove the formed biomass. A reduced biomass formation rate can be achieved by limiting the supply of some nutrient, such as phosphate or potassium, although this does often also reduce the reactor's performance (Kennes and Veiga, 2002). The continuous removal of formed biomass is suitable to operate a trickle-bed reactor under steady state with respect to interfacial area and mass transfer resulting in a constant elimination capacity. This was also the option used in the present work, in which feeding the liquid phase at a relatively high flow rate allowed reducing pressure drop. Overall, the co-treatment of $\mathrm{H}_{2} \mathrm{~S}$ and methanol in a single-stage low-pH biotrickling filter packed with Pall rings is promising. However, the optimization of operational parameters such as limiting the pressure drop still needs some further research. 


\section{Conclusions}

The results show that the co-treatment of $\mathrm{H}_{2} \mathrm{~S}$ and methanol in a single-stage low-pH biotrickling filter is feasible after growth and adaptation of acidophilic methanolconsuming populations. In the originally autotrophic biotrickling filter treating $\mathrm{H}_{2} \mathrm{~S}$, the introduction of $\mathrm{CH}_{3} \mathrm{OH}$ had no significant influence on $\mathrm{H}_{2} \mathrm{~S}$ removal when the inlet concentration of $\mathrm{CH}_{3} \mathrm{OH}$ was below $18 \mathrm{ppm}$. In the range of 57-81 ppm methanol, the removal of $\mathrm{H}_{2} \mathrm{~S}$ was inhibited by the presence of $\mathrm{CH}_{3} \mathrm{OH}$ and the maximum elimination capacity of $\mathrm{H}_{2} \mathrm{~S}$ dropped from 23.8 to $6.4 \mathrm{~g} \mathrm{~m}^{-3} \mathrm{~h}^{-1}$. After reinoculation of the biotrickling filter with activated sludge, methanol and $\mathrm{H}_{2} \mathrm{~S}$ could successfully be treated at low $\mathrm{pH}$ in a single-stage biotrickling filter packed with Pall rings. The maximum elimination capacity of methanol and $\mathrm{H}_{2} \mathrm{~S}$ reached as high as $236 \mathrm{~g} \mathrm{~m}^{-3} \mathrm{~h}^{-1}$ and $6.4 \mathrm{~g} \mathrm{~m}^{-3} \mathrm{~h}^{-1}$, respectively. The presence of methanol in the system significantly decreased the removal rate of $\mathrm{H}_{2} \mathrm{~S}$ while the removal of methanol was not affected by the presence of $\mathrm{H}_{2} \mathrm{~S}$, despite the low $\mathrm{pH}$ of 2 reached in the filter bed. However, excess biomass growth and sulfur accumulation caused a high pressure drop and consequently inhibition of the biotrickling filter's performance. This single-stage biotrickling filter would be very economical for the co-treatment of odors and toxic organic substances from wastewater treatment plants or pulp and paper industries, among others.

\section{Acknowledgements}

The present research was financed by the Spanish Ministry of Education and Science (Project CTM2004-00427). Yaomin Jin was financially supported through a fellowship of the Agencia Española de Cooperación Internacional (AECI) and the Spanish Ministry of Foreign Affairs.

\section{References}

A. Aizpuru, L. Malhautier, J.C. Roux, J.L. Fanlo

Biofiltration of a mixture of volatile organic emissions

J. Air Waste Manage. Assoc., 51 (2001), pp. 1662-1670

C.J.N. Buisman, B.G. Geraats, P. Ijspeert, G. Lettinga

Optimization of sulfur production in a biotechnological sulfide-removing reactor

Biotechnol. Bioeng., 35 (1990), pp. 50-56

D.E. Chitwood, J.S. Devinny

Treatment of mixed hydrogen sulfide and organic vapors in a rock medium biofilter Water Environ. Res., 73 (2001), pp. 426-435

D.E. Chitwood, J.S. Devinny, F.E. Reynolds Jr.

Evaluation of a two-stage biofilter for treatment of POTW waste air

Environ. Prog., 18 (1999), pp. 212-221

H.H.J. Cox, M.A. Deshusses

Co-treatment of $\mathrm{H}_{2} \mathrm{~S}$ and toluene in a biotrickling filter

Chem. Eng. J., 87 (2002), pp. 101-110 
M. Deshusses, C.T. Johnson, G. Leson

Biofiltration of high loads of ethyl acetate in the presence of toluene

J. Air Waste Manage. Assoc., 49 (1999), pp. 973-979

S.J. Ergas, J. Veir, K. Kinney

Control of dichloromethane emissions using biofiltration

J. Environ. Sci. Heal. A, 31 (1996), pp. 1741-1754

S.-C.J. Hwang, C.-M. Lee, H.-C. Lee, H.F. Pua

Biofiltration of waste gases containing both ethyl acetate and toluene using different combinations of bacterial cultures

J. Biotechnol., 105 (2003), pp. 83-94

A.J.H. Janssen, R. Sleyster, C. van der Kaa, A. Jochemsen, J. Bontsema, G. Lettinga

Biological sulfide oxidation in a fed-batch reactor

Biotechnol. Bioeng., 47 (1995), pp. 327-333

A.J.H. Janssen, S.C. Ma, P. Lens, G. Lettinga

Performance of a sulfide-oxidizing expanded-bed reactor supplied with dissolved oxygen

Biotechnol. Bioeng., 53 (1997), pp. 32-40

Y. Jin, M.C. Veiga, C. Kennes

Autotrophic deodorization of hydrogen sulfide in a biotrickling filter

J. Chem. Technol. Biotechnol., 80 (2005), pp. 998-1004

Y. Jin, M.C. Veiga, C. Kennes

Effects of $\mathrm{pH}, \mathrm{CO}_{2}$, and flow pattern on the autotrophic degradation of hydrogen sulfide in a biotrickling filter

Biotechnol. Bioeng., 92 (2005), pp. 462-471

J.R. Kastner, K.C. Das

Comparison of chemical wet scrubbers and biofiltration for control of volatile organic compounds using GC/MS techniques and kinetic analysis

J. Chem. Technol. Biotechnol., 80 (2005), pp. 1170-1179

C. Kennes, M.C. Veiga

Bioreactors for Waste Gas Treatment

Kluwer Academic Publishers, Dordrecht/Boston/London (2001)

C. Kennes, M.C. Veiga

Inert filter media for the biofiltration of waste gases-characteristics and biomass control Rev. Environ. Sci. Biotechnol., 1 (2002), pp. 201-214

P. Lens, L.H. Pol

Environmental Technologies to Treat Sulfur Pollution: Principles and Engineering IWA Publishing, London (2000) 
P.K.T. Liu, R.L. Gregg, H.K. Sabol, N. Barkley

Engineered biofilter for removing organic contaminants in air

J. Air Waste Manage. Assoc., 44 (1994), pp. 299-303

W.J.H. Okkerse, S.P.P. Ottengraf, B. Osinga-Kuipers, M. Okkerse

Biomass accumulation and clogging in biotrickling filters for waste gas treatment. Evaluation of a dynamic model using dichloromethane as a model pollutant

Biotechnol. Bioeng., 63 (1999), pp. 418-430

V.S. Sologar, Z. Lu, D.G. Allen

Biofiltration of concentrated mixtures of hydrogen sulfide and methanol

Environ. Prog., 22 (2003), pp. 129-136

G.A. Sorial, F.L. Smith, M.T. Suidan, A. Pandit, P. Biswas, R.C. Brenner

Evaluation of trickle bed air biofilter performance for BTEX removal

J. Environ. Eng.-ASCE, 123 (1997), pp. 530-537

M.C. Veiga, M. Fraga, L. Amor, C. Kennes

Biofilter performance and characterization of a biocatalyst degrading alkylbenzene gases

Biodegradation, 10 (1999), pp. 169-176 